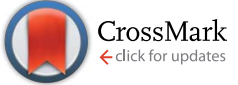

Cite this: Chem. Sci., 2017, 8, 189

\title{
Highly planar diarylamine-fused porphyrins and their remarkably stable radical cations $\uparrow$
}

\author{
Norihito Fukui, ${ }^{a}$ Wonhee Cha, ${ }^{\mathrm{b}}$ Daiki Shimizu, ${ }^{\mathrm{a}}$ Juwon Oh, ${ }^{\mathrm{b}}$ Ko Furukawa, ${ }^{\text {*c }}$ \\ Hideki Yorimitsu, ${ }^{* a}$ Dongho Kim ${ }^{* b}$ and Atsuhiro Osuka*a
}

Oxidative fusion reactions of meso-phenoxazino Ni(॥) porphyrin were found to be temperature dependent, giving rise to either a doubly phenylene-fused product at room temperature or a singly phenoxazine-fused product at $70{ }^{\circ} \mathrm{C}$. The latter was further oxidized to a doubly phenoxazine-fused Ni(॥) porphyrin, which was subsequently converted to the corresponding free base porphyrin and $\mathrm{Zn}(॥)$ porphyrin. Compared to previously reported diphenylamine-fused porphyrins that displayed a molecular twist, doubly phenoxazine-fused porphyrins exhibited distinctly different properties owing to their highly planar structures, such as larger fluorescence quantum yields, formation of an offset face-to-face dimer both in solution and the solid state, and the generation of a mixed-valence $\pi$-radical cation dimer upon electrochemical oxidation. One-electron oxidation of the phenoxazine-fused $\mathrm{Ni}(॥)$ porphyrin with Magic Blue gave the corresponding radical cation, which was certainly stable and could be isolated by separation over a silica gel column but slowly chlorinated at the reactive $\beta$-positions in the solid state. This finding led to us to examine $\beta, \beta^{\prime}$-dichlorinated phenoxazine-fused and diphenylamine-fused $\mathrm{Ni}\left({ }^{\prime}\right)$ porphyrins, which, upon treatment with Magic Blue, provided remarkably stable radical cations to an unprecedented level. It is actually possible to purify these radical cations by silica gel chromatography, and they can be stored for over 6 months without any sign of deterioration. Moreover, they exhibited no degradation even after the $\mathrm{CH}_{2} \mathrm{Cl}_{2}$ solution was washed with water. However, subtle structural differences (planar versus partly twisted) led to different crystal packing structures and solid-state magnetic properties.

Received 21st June 2016 Accepted 30th July 2016 DOI: $10.1039 / \mathrm{c} 6 \mathrm{sc} 02721 \mathrm{k}$ www.rsc.org/chemicalscience

\section{Introduction}

Radical cations of porphyrins have been long studied because they are involved as key intermediates in the crucial steps of photosynthesis and enzymatic oxidation cycles. ${ }^{1}$ To reveal the key roles and specific molecular attributes that are necessary for relevant functions, fundamental properties of radical cations of porphyrins have been continuously investigated. ${ }^{2-4}$ As representative examples, Wolberg and Manassen prepared radical cations of $\mathrm{Ni}$ (II), $\mathrm{Zn}$ (II), $\mathrm{Cu}$ (II), $\mathrm{Co}$ (III), and $\mathrm{Fe}$ (III) tetraphenylporphyrins by electrochemical oxidation, and studied the optical, electrochemical, and magnetic properties. ${ }^{2 d, e}$ Furthermore, detailed structures and reactivities of various

\footnotetext{
${ }^{a}$ Department of Chemistry, Graduate School of Science, Kyoto University, Sakyo-ku, Kyoto 606-8502, Japan. E-mail: yori@kuchem.kyoto-u.ac.jp; osuka@kuchem.kyoto-u. ac.jp

${ }^{b}$ Spectroscopy Laboratory of Functional $\pi$-Electronic Systems and Department of Chemistry, Yonsei University, Seoul 120-749, Korea. E-mail: dongho@yonsei.ac.kr

${ }^{c}$ Center for Instrumental Analysis, Niigata University, Nishi-ku, Niigata 950-2181, Japan. E-mail: kou-f@chem.sc.niigata-u.ac.jp

$\dagger$ Electronic supplementary information (ESI) available. CCDC 1469154-1469160. For ESI and crystallographic data in CIF or other electronic format see DOI: $10.1039 / \mathrm{c} 6 \mathrm{sc} 02721 \mathrm{k}$
}

porphyrin radical cations have also been successively explored. ${ }^{3,4}$

In recent years, stable organic radicals have attracted increasing attention in light of their potential application in organic electronics, photonics, spintronics, and energy storage devices. ${ }^{5}$ Considering the rich chemistry of porphyrins, exploration of highly stable radical cations of porphyrins that can be isolated and manipulated as usual organic closed-shell molecules is a promising approach worthy of a challenge. However, such stable radical cations of porphyrins have been quite rare despite the extensive number of investigations mentioned above.

Generally, radical cations of porphyrins are reactive and undergo facile degradation under ambient conditions. For instance, a half-life of a radical cation of $\mathrm{Ni}$ (II) tetraphenylporphyrin was found to be only 5 minutes at room temperature in benzonitrile solution containing $n \mathrm{Bu}_{4} \mathrm{NBF}_{4}$ as a supporting electrolyte. $^{2 d}$ Therefore, isolation of such inherently reactive porphyrin radical cations usually required careful manipulations under strictly inert atmosphere, purposefully avoiding conventional work-up procedures and silica-gel column chromatography in open air. ${ }^{3}$ The instability of radical cations of porphyrins can be ascribed to their high oxidizing power and 
poor kinetic protection toward a wide range of nucleophiles and reducing reagents. Actually, Tsuchiya reported that stability of a oxo-Fe(Iv) porphyrin radical cation was improved by exhaustive introduction of phenyl groups both at the meso- and $\beta$-positions. ${ }^{4 b}$ However, even in the case of such a sterically protected radical cation, the reactivity remained relatively high, and the physical measurements had to be performed below $8{ }^{\circ} \mathrm{C}$. To provide an extremely stable porphyrin radical cation that can be handled like a usual closed-shell molecule, effective employment of both thermodynamic and kinetic stabilization is of paramount importance as observed in stable neutral radicals of other porphyrins and porphyrinoids. ${ }^{6}$

As an effective structural motif to realize a stable radical cation, planar triarylamines possessing an embedded nitrogen atom are known (Chart 1$).^{7}$ While a triphenylaminium radical was reported to be unstable and coupled at the para-positions to give its dimer even under inert atmosphere, ${ }^{8}$ Hellwinkel and co-workers reported a pioneering work that a methylenebridged planar triarylamine $\mathbf{1}$ provided a stable radical cation via one-electron oxidation in concentrated sulfuric acid or trifluoroacetic acid. ${ }^{7 a, b}$ Recently, other researchers extended this work to include more stable radical cations of planar triaryamines such as $\mathbf{1}$ and $2 .^{7 c-g}$ However, preparation of these radical cations always required anaerobic and/or anhydrous conditions.

As an intriguing aspect, Okada et al. found that planarity of radical cations played a crucial role in the packing structures. ${ }^{7 c, d}$ Namely, a radical cation of oxygen-linked planar triarylamine 2 packed as a dimer due to the high planarity, exhibiting a strong antiferromagnetic interaction in the solid state, while a radical cation of partially linked twisted congener 3 showed a threedimensionally connecting weak antiferromagnetic interaction instead of such dimer formation.

With these examples in mind, we envisioned the exploration of very stable radical cations of porphyrins by incorporating a fused diarylamine unit directly at the porphyrin periphery. Here, we report the first synthesis of doubly phenoxazine-fused porphyrins $\mathbf{4 M}$ as highly planar nitrogen-embedded porphyrins and the isolation of a radical cation of phenoxazine-fused $\mathrm{Ni}(\mathrm{II})$ porphyrin, $[\mathbf{4 N i}]^{+}$, as a certainly stable molecule. Furthermore, we found that $\beta, \beta^{\prime}$-dichlorination of $[4 \mathbf{N i}]^{+}$ enhanced its chemical stability remarkably, so that it could withstand usual aqueous work up procedures and be stored under ambient conditions without any deterioration over several months.

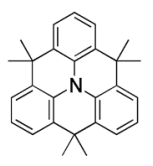

1

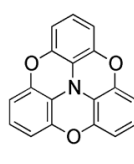

2

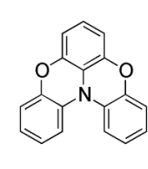

3

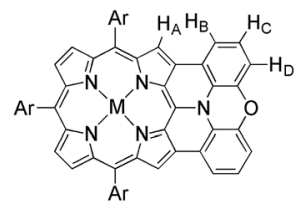

$4 \mathrm{M}(\mathbf{M}=\mathrm{Ni}, 2 \mathrm{H}, \mathrm{Zn})$
Chart 1 Structures of internally bridged triphenylamines 1-3 and phenoxazine-fused porphyrin $4 \mathrm{M}$.

\section{Results and discussion}

\section{Preparation of fully phenoxazine-fused porphyrins}

The synthesis of phenoxazine-fused porphyrins $\mathbf{4 M}$ is depicted in Scheme 1. Previously, we reported that an oxidative fusion reaction of meso-[bis(3-methoxyphenyl)amino]porphyrin 5 with 2,3-dichloro-5,6-dicyano- -benzoquinone (DDQ) and $\mathrm{FeCl}_{3}$ at room temperature provided $\beta, \beta^{\prime}$-dichlorinated diarylaminefused porphyrin $\mathbf{6 .}^{\mathbf{9 a 1 0}}$ In sharp contrast, the oxidation of 5-phenoxazino $\mathrm{Ni}$ (II) porphyrin 7 under similar reaction conditions resulted in fusion of the 10,20-aryl groups at the 12- and 18-positions, yielding doubly phenylene-fused porphyrin $\mathbf{8}$. We speculated that the formation of $\mathbf{8}$ might be ascribed to a high rotational barrier of the phenoxazinyl substituent after oneelectron oxidation of the phenoxazine segment. The oxidized phenoxazine segment would remain rather perpendicular to the
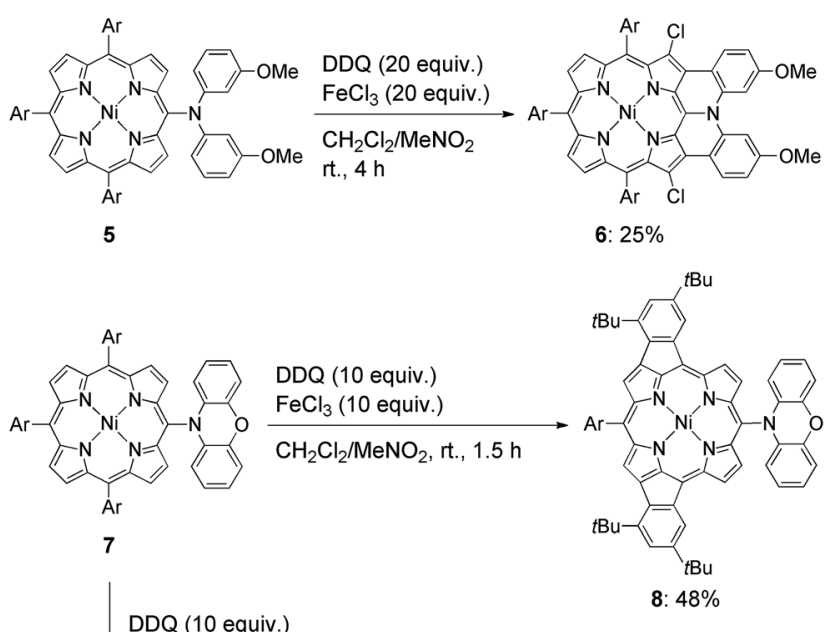

$\mathrm{Sc}(\mathrm{OTf})_{3}(10$ equiv. $\mathrm{CICH}_{2} \mathrm{CH}_{2} \mathrm{Cl} / \mathrm{MeNO}_{2}, 70^{\circ} \mathrm{C}, 1 \mathrm{~h}$

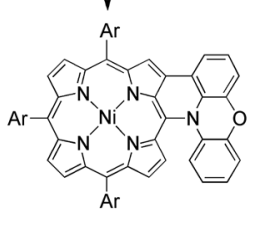

9: $58 \%$

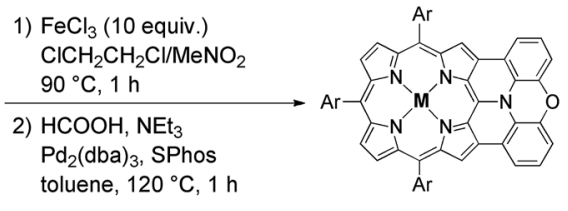

toluene, $120^{\circ} \mathrm{C}, 1 \mathrm{~h}$
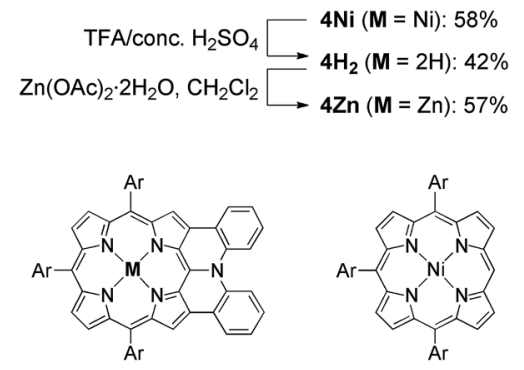

$10 \mathrm{Ni}(\mathrm{M}=\mathrm{Ni})$

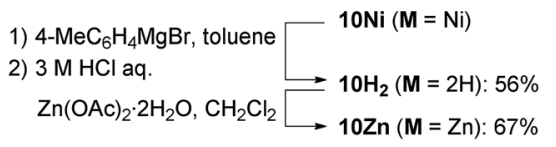

Scheme 1 Synthesis of $\beta, \beta^{\prime}$-dichlorinated diarylamine-fused porphyrin 6 , phenylene-fused porphyrin 8 , doubly phenoxazine-fused porphyrins $4 \mathrm{M}$, and diphenylamine-fused porphyrins $10 \mathrm{M}$. Structure of triaryl Ni(I)-porphyrin 11Ni. Ar = 3,5-di-tert-butylphenyl. 
porphyrin plane, hence serving as an electron-withdrawing group and causing the fusion of the 10,20-phenyl groups at the 12- and 18-positions. This consideration came from our previous study that electron-withdrawing substituents at the meso-position induced a similar double phenylene-fusion reaction at the opposite side. ${ }^{\mathbf{1 1}}$ Therefore, we examined the reaction at higher temperature to facilitate the rotation of the meso-phenoxazinyl substituent. To our delight, the oxidation of 7 with $\mathrm{FeCl}_{3}$ at $90{ }^{\circ} \mathrm{C}$ led to the formation of phenoxazine-fused porphyrins together with phenylene-fused porphyrin 8. We chose a combination of DDQ and $\mathrm{Sc}(\mathrm{OTf})_{3}$ as a weaker oxidant in order to suppress over-oxidation. After the extensive optimization of reaction conditions, the reaction at $70{ }^{\circ} \mathrm{C}$ proceeded nicely to provide singly phenoxazine-fused porphyrin 9 in $58 \%$ yield. Interestingly, the formation of $\mathbf{8}$ was not observed under these conditions. In 9, the phenoxazine segment is held in coplanar fashion with respect to the porphyrin core, a geometrically ideal arrangement for realizing complete fusion. Complete fusion was easily achieved by further oxidation with $\mathrm{FeCl}_{3}$, giving doubly fused products with partial chlorination at the pyrrolic $\beta$-position adjacent to the fusion site as observed in the synthesis of $\mathbf{6}$. Separation of these doubly fused products was tedious and thus their dechlorination ${ }^{9 a, 12}$ was attempted with $\mathrm{NEt}_{3}$ and $\mathrm{HCOOH}$ under $\mathrm{Pd} / \mathrm{SPhos}^{13}$ catalysis, which furnished $4 \mathrm{Ni}$ in $58 \%$ yield. Removal of the central nickel atom of 4Ni was achieved upon treatment with concentrated sulfuric acid in trifluoroacetic acid (TFA) at $0{ }^{\circ} \mathrm{C}$ to provide free base $\mathbf{4} \mathbf{H}_{2}$ in $42 \%$ yield, and subsequent zinc-complexation with $\mathrm{Zn}(\mathrm{OAc})_{2} \cdot 2 \mathrm{H}_{2} \mathrm{O}$ afforded the $\mathrm{Zn}$ complex $4 \mathrm{Zn}$ in $57 \%$ yield. As a reference, doubly diphenylamine-fused free base porphyrin $\mathbf{1 0 H}_{2}$ was synthesized by denickelation of previously reported diphenylamine-fused porphyrin $\mathbf{1 0 N \mathbf { N i } ^ { \mathbf { 9 } }}$ with $p$-tolylmagnesium bromide followed by demagnesiation with $3 \mathrm{M} \mathrm{HCl}$ aq. in $56 \%$ yield. ${ }^{14}$ The zinc complex $10 \mathrm{Zn}$ was also prepared by zinccomplexation of with $\mathrm{Zn}(\mathrm{OAc})_{2} \cdot 2 \mathrm{H}_{2} \mathrm{O}$ in $67 \%$ yield.

\section{Optical properties}

The UV/Vis absorption and emission spectra of $\mathbf{4} \mathbf{H}_{\mathbf{2}}, \mathbf{1 0} \mathbf{H}_{\mathbf{2}}, \mathbf{4 Z n}$ and $10 \mathrm{Zn}$ in $\mathrm{CH}_{2} \mathrm{Cl}_{2}$ are shown in Fig. 1. The absorption spectrum of 10Zn exhibits a split Soret band at 439 and $453 \mathrm{~nm}$, and Q-bands at 585 and $632 \mathrm{~nm}$, while that of $\mathbf{4 Z n}$ shows a distinct Soret band at $450 \mathrm{~nm}$ and slightly red-shifted Q-bands at 591 and $640 \mathrm{~nm}$. Similarly, $\mathbf{4} \mathbf{H}_{2}$ displays an intense Soret band at $452 \mathrm{~nm}$ and red-shifted Q-bands at 549, 591, 620 and $680 \mathrm{~nm}$. Compared to $\mathbf{1 0 H}_{2}$ and $\mathbf{1 0 Z n}$, the slightly red-shifted absorption spectral features of $\mathbf{4} \mathbf{H}_{\mathbf{2}}$ and $\mathbf{4 Z n}$ suggest that the fused phenoxazine group leads to a more planar geometry with efficient extension of $\pi$-conjugation over the whole molecule.

The fluorescence spectra of $\mathbf{4 H _ { 2 }}, \mathbf{4 Z n}, \mathbf{1 0 H _ { 2 }}$ and $10 \mathrm{Zn}$ are observed at 686, 648, 683, and $640 \mathrm{~nm}$, respectively. The observed fluorescence quantum yields $\left(\Phi_{\mathrm{F}}\right)$ and fluorescence lifetimes $(\tau)$, calculated radiative decay rates $\left(k_{\mathrm{r}}\right)$, and nonradiative decay rates $\left(k_{\mathrm{nr}}\right)$ are summarized in Table 1 . The fluorescence quantum yields of $4 \mathrm{H}_{2}, 4 \mathrm{Zn}, 10 \mathrm{H}_{2}$ and $10 \mathrm{Zn}$ are distinctly larger than those of tetraphenylporphyrinato zinc(II) (0.033) and tetraphenylporphyrin (0.11). ${ }^{15}$ As suggested in
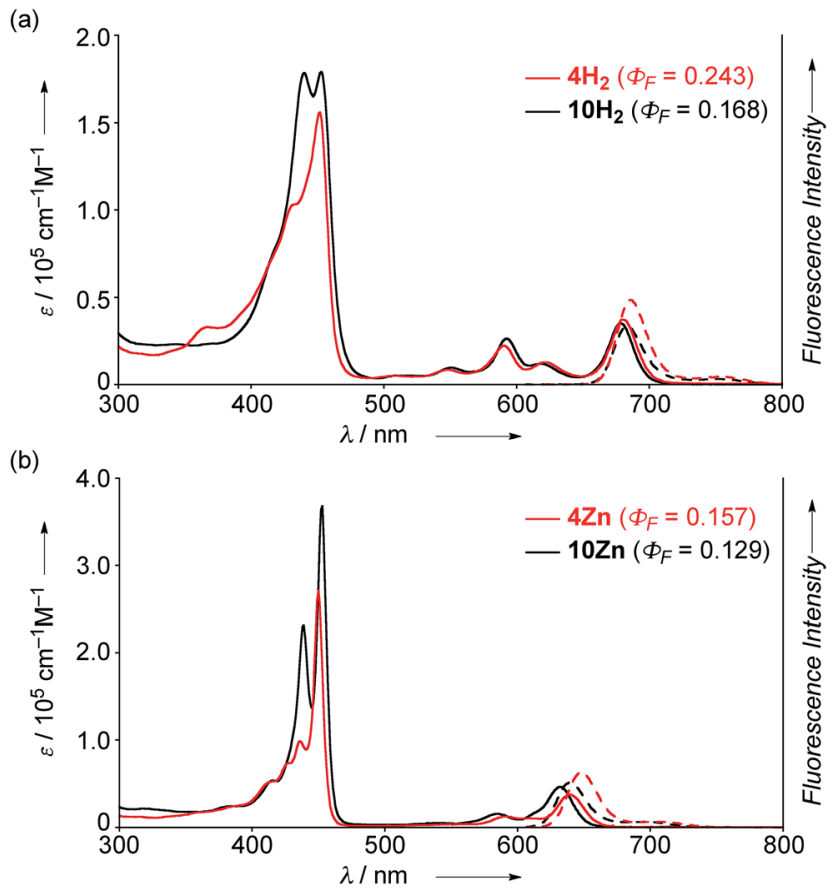

Fig. 1 UV/Vis absorption and emission spectra of (a) $4 \mathrm{H}_{2}$ and $10 \mathrm{H}_{2}$, and (b) $4 \mathrm{Zn}$ and $10 \mathrm{Zn}$ in $\mathrm{CH}_{2} \mathrm{Cl}_{2} \cdot \varepsilon=$ extinction coefficient.

a previous report, ${ }^{9 a}$ effective conjugation of the embedded nitrogen atom with the porphyrin network may increase the radiative decay rate while less conformational flexibility associated with the fused structure is expected to decrease nonradiative decay. Therefore, the larger radiative decay rates of $\mathbf{4 H}$ and $4 \mathrm{Zn}$ compared to those of $\mathbf{1 0 H}_{2}$ and $10 \mathrm{Zn}$ are attributable to effective conjugation of the nitrogen atom due to enhanced planarity, and the smaller non-radiative decay rates can be ascribed to the more rigid structures.

\section{X-ray structures of $4 \mathrm{Ni}$ and $10 \mathrm{Ni}$}

The X-ray crystal structures of $\mathbf{4 N i}$ and $10 \mathrm{Ni}$ are shown in Fig. 2. ${ }^{16}$ 10Ni exhibits a distorted structure as indicated by a dihedral angle of $32^{\circ}$ between the two phenyl groups in the fused-diphenylamine unit. This molecular twist is considered to arise from intramolecular steric congestion between the two ortho-hydrogen atoms of the phenyl groups. In contrast, $4 \mathbf{N i}$ takes on a slightly wavy but more planar structure with a small dihedral angle of $4^{\circ}$ between the relevant two phenyl groups. The mean plane deviation (MPD) of $\mathbf{4 N i}$ was calculated to be $0.157 \AA$, which is apparently smaller than that of $10 \mathrm{Ni}$ $(0.209 \AA) .{ }^{17}$ In the crystals, both $4 \mathbf{N i}$ and $10 \mathrm{Ni}$ form face-to-face

Table 1 Optical properties of $4 \mathrm{H}_{2}, 4 \mathrm{Zn}, 10 \mathrm{H}_{2}$, and $10 \mathrm{Zn}$

\begin{tabular}{lllll}
\hline & $\Phi_{\mathrm{F}}$ & $\tau[\mathrm{ns}]$ & $k_{\mathrm{r}}\left[\mathrm{s}^{-1}\right]$ & $k_{\mathrm{nr}}\left[\mathrm{s}^{-1}\right]$ \\
\hline $\mathbf{4} \mathbf{H}_{2}$ & 0.243 & 6.0 & $4.7 \times 10^{7}$ & $1.3 \times 10^{8}$ \\
$\mathbf{4 Z n}$ & 0.157 & 2.7 & $5.9 \times 10^{7}$ & $3.1 \times 10^{8}$ \\
$\mathbf{1 0 H}$ & 0.168 & 4.8 & $3.5 \times 10^{7}$ & $1.7 \times 10^{8}$ \\
$\mathbf{1 0 Z n}$ & 0.129 & 2.5 & $5.2 \times 10^{7}$ & $3.5 \times 10^{8}$
\end{tabular}


(a)

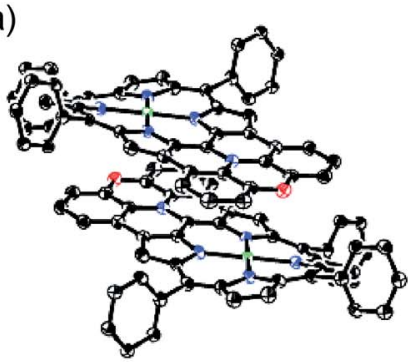

(d)

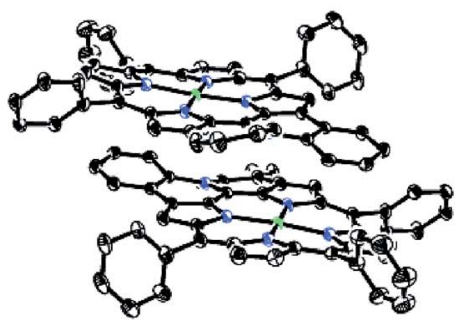

(b)

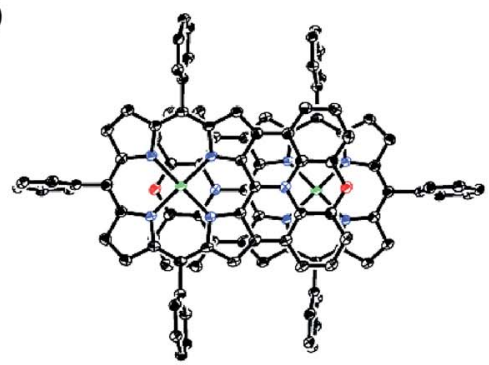

(e)

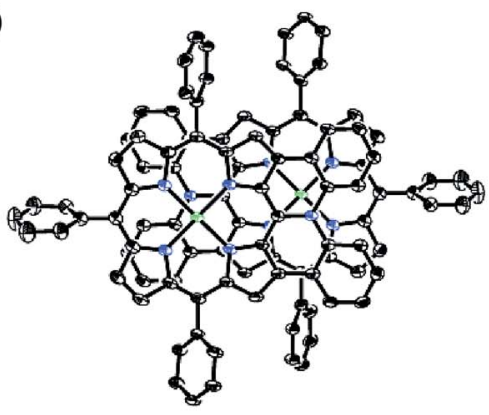

(c)

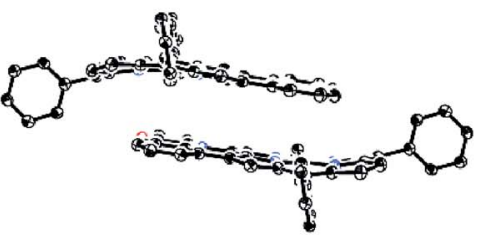

(f)

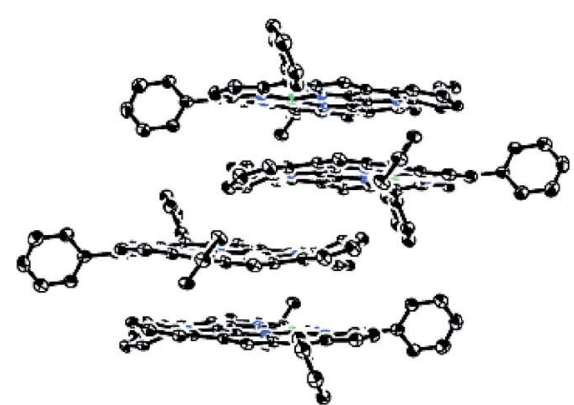

Fig. 2 X-Ray crystal structures of $4 \mathrm{Ni}$ and $10 \mathrm{Ni}$. (a) Over view, (b) top view, and (c) side view of dimeric $4 \mathrm{Ni}$. (d) Over view and (e) top view of dimeric $10 \mathrm{Ni}$. (f) Side view of packing structure of $10 \mathrm{Ni}$. Thermal ellipsoids are drawn at the $50 \%$ probability level. Solvent molecules, tert-butyl groups, and all hydrogen atoms are omitted for clarity.

dimers with the dipole moment arranged in an offset manner. In the case of $\mathbf{1 0 N i}$, such dimer units are packed to form a onedimensional columnar structure while dimers of $4 \mathbf{N i}$ are isolated from each other. Reflecting the more planar structure, the interporphyrin separation distance in the dimer of $\mathbf{4 N \mathbf { N }}$ is distinctly shorter (3.392 ̊̊) than that of 10Ni (3.655-3.734 $\mathrm{A})$.

\section{Dimerization in $\mathrm{CDCl}_{3}$}

Phenoxazine-fused porphyrin $\mathbf{4 N \mathbf { N }}$ was found to exhibit a concentration-dependent ${ }^{1} \mathrm{H}$ NMR spectrum in $\mathrm{CDCl}_{3}$ at $298 \mathrm{~K}$, as observed in other $\pi$-stacking dimers (Fig. 3a). ${ }^{18}$ The ${ }^{1} \mathrm{H}$ NMR spectrum of $4 \mathrm{Ni}$ in $\mathrm{CDCl}_{3}$ at $10 \mathrm{mM}$ showed signals of $\mathrm{H}_{\mathrm{A}}$, $\mathrm{H}_{\mathrm{B}}, \mathrm{H}_{\mathrm{C}}$, and $\mathrm{H}_{\mathrm{D}}$ at 8.91, 8.00, 7.22, and $6.51 \mathrm{ppm}$, respectively. They were downfield shifted at $1.0 \mathrm{mM}$, being observed at 9.12, 8.31, 7.55, and $7.16 \mathrm{ppm}$, respectively. The observed down-field shifts at low concentration were larger for signals due to the protons at the fused-phenoxazine moiety; namely in the order of $\mathrm{H}_{\mathrm{A}}(0.23 \mathrm{ppm})<\mathrm{H}_{\mathrm{B}}(0.31 \mathrm{ppm})<\mathrm{H}_{\mathrm{C}}(0.33 \mathrm{ppm})<\mathrm{H}_{\mathrm{D}}(0.65 \mathrm{ppm})$. In contrast, the down-field shifts were very small or negligible for signals due to the pyrrolic $\beta$-protons at the porphyrin moiety.

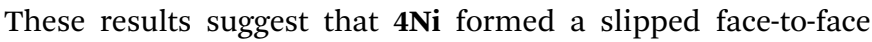
dimer overlapping at the phenoxazine moiety as observed in the solid state.

The concentration dependent ${ }^{1} \mathrm{H}$ NMR chemical shifts were analyzed by the Saunders-Hyne method, which led to the conclusion that a monomer-dimer equilibration model was apparently superior to fit the observed spectra over a monomertrimer equilibration model (Fig. 4). ${ }^{19}$ Then, the association constant has been estimated to be $7.2 \times 10 \mathrm{M}^{-1}$ for $4 \mathrm{Ni}$ by ${ }^{1} \mathrm{H}$ NMR dilution experiment based on the Horman-Doreux model. ${ }^{20}$ Complexes $\mathbf{4 H}_{2}$ and $\mathbf{4 Z n}$ also showed similar concentration-dependent ${ }^{1} \mathrm{H}$ NMR spectra, and the association constants of $4 \mathbf{H}_{2}$ and $\mathbf{4 Z n}$ have been estimated to be $2.9 \times$ $10 \mathrm{M}^{-1}$ and $1.0 \times 10^{2} \mathrm{M}^{-1}$, respectively. In contrast, the ${ }^{1} \mathrm{H} \mathrm{NMR}$

(a) $4 \mathrm{Ni}$

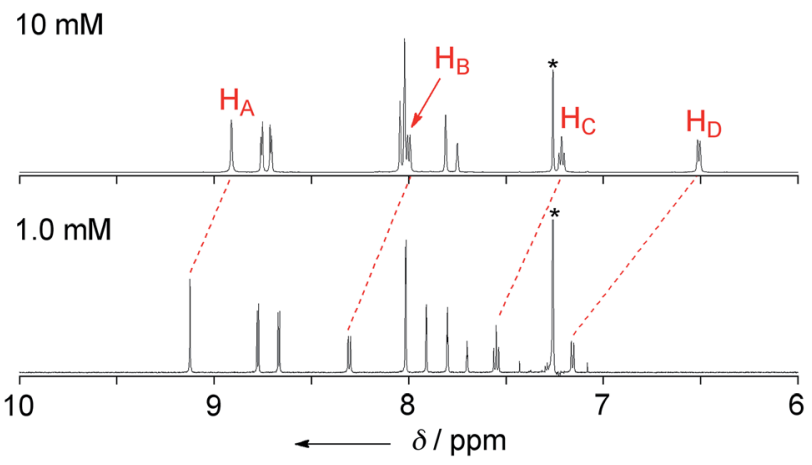

(b) $10 \mathrm{Ni}$

$40 \mathrm{mM}$
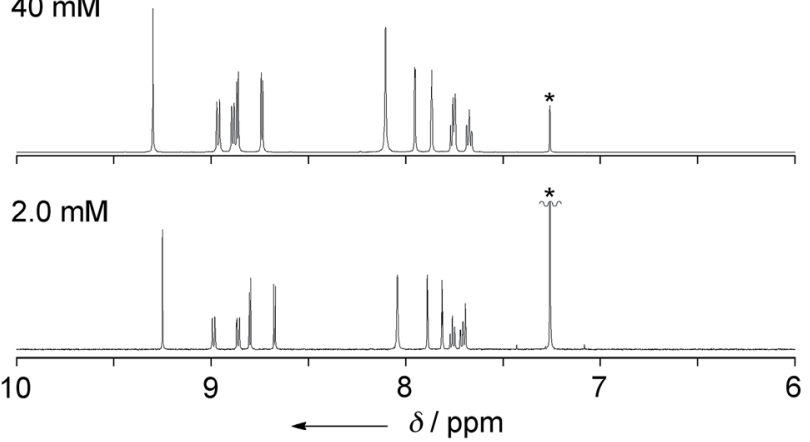

Fig. $3{ }^{1} \mathrm{H}$ NMR spectra of (a) $4 \mathrm{Ni}$ and (b) $10 \mathrm{Ni}$ in $\mathrm{CDCl}_{3}$ under different concentrations at $298 \mathrm{~K}$. * Residual $\mathrm{CHCl}_{3}$. 


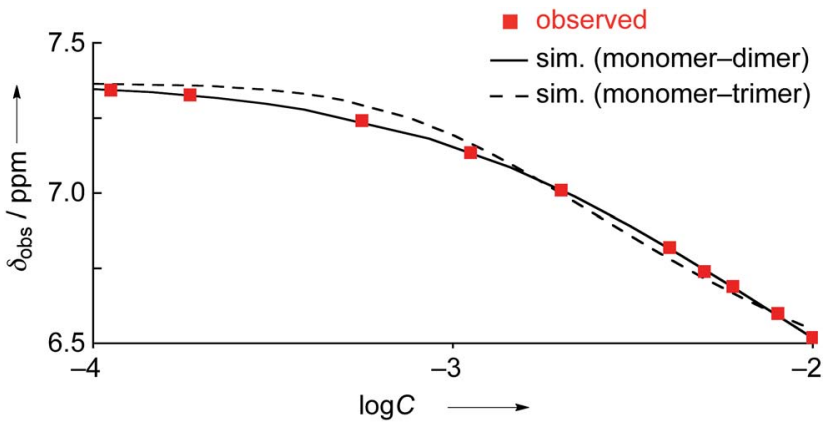

Fig. $4{ }^{1} \mathrm{H}$ NMR dilution curves obtained for $4 \mathrm{Ni}$ in $\mathrm{CDCl}_{3}$. Red squares: observed values, solid line: simulated curve as the monomer-dimer model, and dashed line: simulated curve as the monomer-trimer model.

spectrum of diphenylamine-fused porphyrin 10Ni showed negligible concentration dependence (Fig. 3b), and the association constant was estimated to be at most below $1 \mathrm{M}^{-1}$. Similarly, the ${ }^{1} \mathrm{H}$ NMR spectra of $\mathbf{1 0 H}_{2}$ and $10 \mathrm{Zn}$ were also almost independent of the concentration. Therefore, it can be concluded that the structural difference in the fused diarylamine part; a noncyclic diphenylamine in $\mathbf{1 0 M}$ versus a cyclic phenoxazine in $\mathbf{4 M}$, leads to contrasting assembling behaviors in $\mathrm{CDCl}_{3}$.

\section{Electrochemistry}

The electrochemical properties of $4 \mathbf{N i}$ and $\mathbf{1 0 N i}$ were studied by cyclic voltammetry (CV) and differential pulse voltammetry (DPV) in $\mathrm{CH}_{2} \mathrm{Cl}_{2}$ (Fig. 5). Diphenylamine-fused porphyrin 10Ni showed three reversible oxidation waves at $0.15,0.72$, and

(a) $10 \mathrm{Ni}$

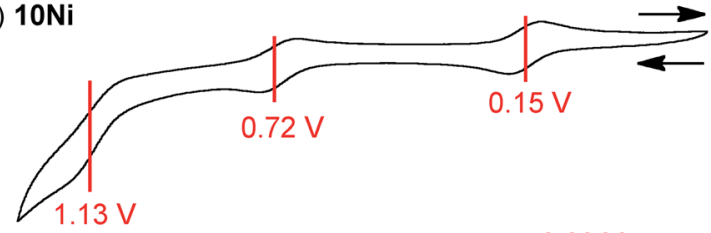

(b) $4 \mathrm{Ni}(2.2 \mathrm{mM})$
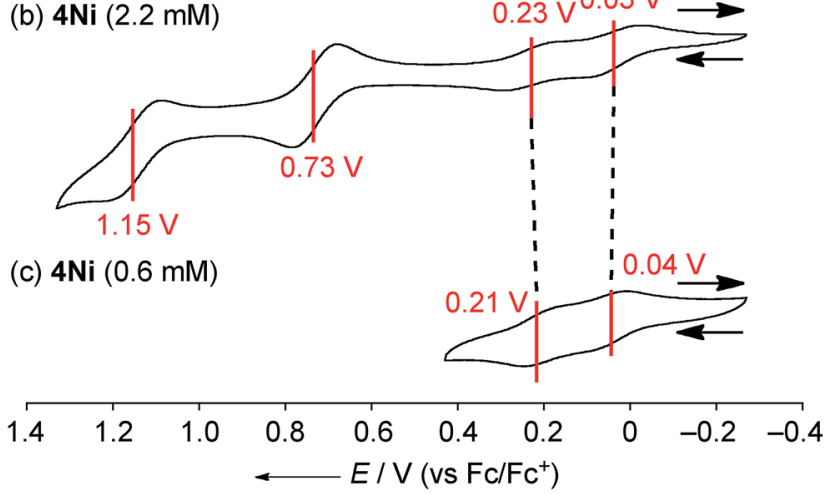

Fig. 5 Cyclic voltammograms of (a) $10 \mathrm{Ni}$, (b) $4 \mathrm{Ni}$ at $2.2 \mathrm{mM}$, and (c) $4 \mathrm{Ni}$ at $0.6 \mathrm{mM}$. The redox potentials were measured by cyclic voltammetry in anhydrous $\mathrm{CH}_{2} \mathrm{Cl}_{2}$ with $0.1 \mathrm{MnBu}_{4} \mathrm{NPF}_{6}$ as a supporting electrolyte, and $\mathrm{Ag} / \mathrm{AgClO}_{4}$ as a reference electrode. The ferrocene/ferrocenium ion couple was used as an external reference. Scan rate: $0.05 \mathrm{~V} \mathrm{~s}^{-1}$.
$1.13 \mathrm{~V}$, and one reversible reduction wave at $-1.84 \mathrm{~V}$. Phenoxazine-fused porphyrin $\mathbf{4 N i}$ showed four reversible oxidation waves at $0.03,0.23,0.73$, and $1.15 \mathrm{~V}$, and one reversible reduction wave at $-1.83 \mathrm{~V}$. These oxidation potentials of $4 \mathrm{Ni}$ showed apparent negative shifts compared to those of meso-phenoxazino Ni(II) porphyrin $7(0.34 \text { and } 0.89 \mathrm{~V})^{9 a}$ and 5,10,15-tris(3,5di-tert-butylphenyl)porphyrinato nickel(II) 11 (0.56 and $0.82 \mathrm{~V}$ ). ${ }^{21}$ These results indicate that the embedding of a nitrogen atom directly at the periphery led to an increase of the electrondonating ability of the substituent. On the other hand, the reduction potential of $\mathbf{4 N i}$ remains almost unchanged compared to those of $7(-1.80 \mathrm{~V})$ and $\mathbf{1 1}(-1.75 \mathrm{~V})$.

DPV experiments revealed that the electrochemical oxidation of $10 \mathrm{Ni}$ proceeded via usual $1 \mathrm{e} / 1 \mathrm{e} / 1 \mathrm{e}$ processes. On the other hand, those of $\mathbf{4 N i}$ proceeded through $0.5 \mathrm{e} / 0.5 \mathrm{e} / 1 \mathrm{e} / 1 \mathrm{e}$ oxidation process for one porphyrin unit. These waves were similar to electrochemical responses of the other porphyrin complex, ${ }^{22 a}$ phthalocyanine, ${ }^{22 b} \mathrm{Ru}(\mathrm{II})$ polypyridyl complexes, ${ }^{22 c-e}$ and tetrathiafulvalene derivatives, ${ }^{22 f, g}$ all containing planar aromatic units capable of forming $\pi$-dimers. An association constant of $4 \mathrm{Ni}$ in $\mathrm{CH}_{2} \mathrm{Cl}_{2}$ has been estimated to be $8.2 \times 10^{2} \mathrm{M}^{-1}$ by dilution experiment of the UV/Vis absorption spectra, which is almost 10 times larger than that in $\mathrm{CDCl}_{3}$. In addition, $\Delta E$ values $\left(E_{\mathrm{ox} 2}{ }^{1 / 2}-E_{\mathrm{ox} 1}{ }^{1 / 2}\right)$ of $4 \mathrm{Ni}$ are only weakly concentrationdependent; $0.20 \mathrm{~V}$ at $2.2 \mathrm{mM}$ and $0.17 \mathrm{~V}$ at $0.6 \mathrm{mM}$, as observed in other $\pi$-systems. ${ }^{22}$ Thus, the split first oxidation waves of $4 \mathbf{N i}$ can be interpreted in terms of the generation of a mixed-valence $\pi$-radical cation dimer comprised of neutral and radical cation species. ${ }^{3 d, 22,23}$ Therefore, the $\Delta E$ values $(0.17-0.20 \mathrm{~V})$, which represent the degree of the electronic interaction in the dimer, are comparable to those of previously reported porphyrin dimers $(0.07-0.31 \mathrm{~V}) .{ }^{24}$ After the second oxidation, the generated cation radicals are dissociated due to coulombic repulsion and undergo the third and fourth oxidations similarly to 10Ni.

\section{Isolation of radical cations}

Isolation of the radical cation of $\mathbf{4 N i}$ was attempted (Scheme 2). Porphyrin 4Ni was oxidized with tris(4-bromophenyl)aminium hexachloroantimonate (Magic Blue), and radical cation $[\mathbf{4 N i}]^{+}$ was obtained in $49 \%$ yield after separation over a silica gel column in the open air. Radical cation $[\mathbf{4 N i}]^{+}$was certainly stable but was susceptible to gradual chlorination in the solid state, providing $\beta$-chlorinated porphyrin 12. Therefore, we protected the most reactive $\beta$-positions of $4 \mathbf{N i}$ by chlorination with 2-chloro-1,3-bis(methoxycarbonyl)guanidine (Palau'Chlor) ${ }^{25}$ to produce 13 in $77 \%$ yield. The dimerization constant of 13 in $\mathrm{CDCl}_{3}$ has been evaluated to be $7.0 \times 10^{2} \mathrm{M}^{-1}$ by ${ }^{1} \mathrm{H}$ NMR titration experiments. This association constant is considerably larger than those of $\mathbf{4 M}$, because of the electron-withdrawing chloro groups that facilitate $\pi-\pi$ stacking through reducing the $\pi$-electron density of the porphyrin core. ${ }^{26}$ Then, one-electron oxidation of $\mathbf{1 3}$ was attempted with Magic Blue under similar conditions. The oxidation proceeded smoothly to produce radical cation [13] $]^{+}$in $79 \%$ yield after separation over a silica gel column. Surprisingly, radical cation [13] $]^{+}$is remarkably stable under ambient conditions, which is underlined by the facts that 

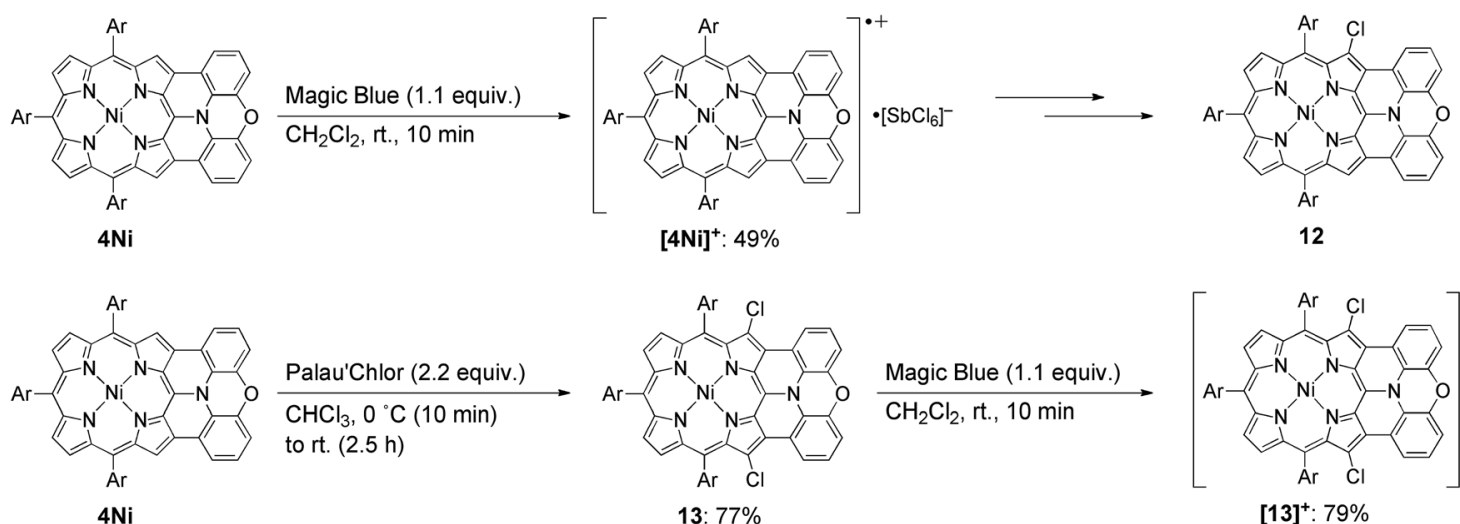

Palau'Chlor (2.2 equiv.) $\mathrm{CHCl}_{3}, 0^{\circ} \mathrm{C}(10 \mathrm{~min})$ to rt. $(2.5 \mathrm{~h})$
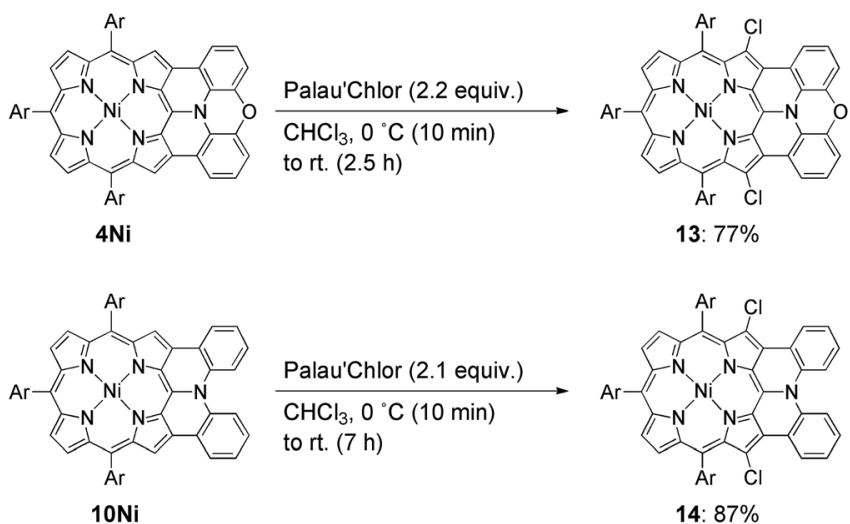

Magic Blue (1.1 equiv.) $\mathrm{CH}_{2} \mathrm{Cl}_{2}$, rt., 10 min
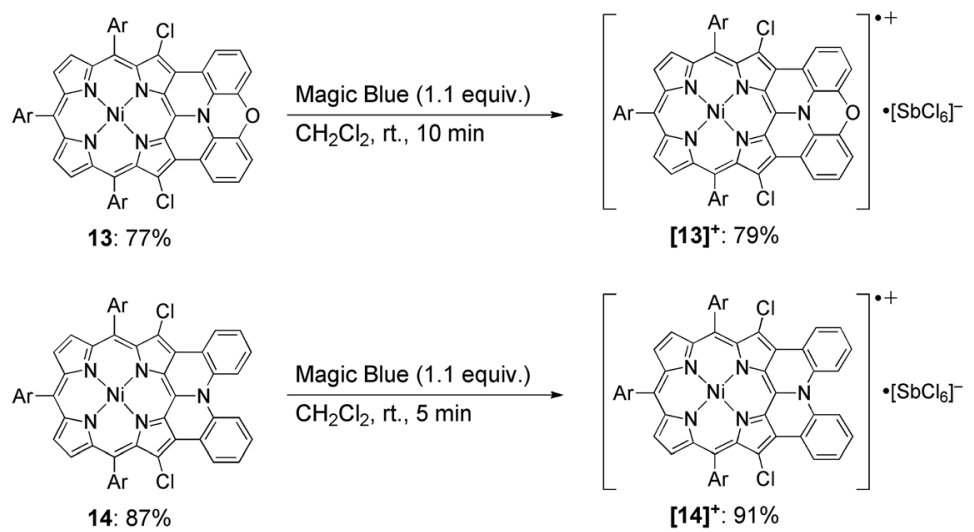

Scheme 2 Synthesis of radical cations $\left[4 \mathrm{Ni}^{+},[13]^{+}\right.$, and $[14]^{+} . \mathrm{Ar}=3,5$-di-tert-butylphenyl.

(1) $[\mathbf{1 3}]^{+}$can be stored under ambient conditions over 6 months without any detectable decomposition, (2) the absorption spectrum of $[13]^{+}$remained unchanged after being kept as a tetrachloroethane solution at $70^{\circ} \mathrm{C}$ for $1 \mathrm{~h},(3)[13]^{+}$can be purified by silica-gel column chromatography, and (4) $[13]^{+}$was inert to moisture, and when a solution of [13] ${ }^{+}$in $\mathrm{CH}_{2} \mathrm{Cl}_{2}$ was washed with water, no decomposition was observed. Similarly, porphyrin 10Ni was converted to the corresponding $\beta, \beta^{\prime}$-dichloroporphyrin 14 by chlorination with Palau'Chlor, and subsequent oxidation with Magic Blue gave [14] ${ }^{+}$in $79 \%$ yield in two steps. Radical cation $[\mathbf{1 4}]^{+}$is also extremely stable, being comparable to $[\mathbf{1 3}]^{+}$.

\section{X-ray crystal structures of radical cations}

$\mathrm{X}$-Ray diffraction analysis unambiguously revealed the structures of 13, 14, $[13]^{+}$, and $[14]^{+}$(Fig. 6). ${ }^{27}$ In the structures of $[13]^{+}$ and $[\mathbf{1 4}]^{+}$, each porphyrin unit carries one counter anion. Selected structural factors are summarized in Table 2. In each compound, the sum of $\mathrm{C}-\mathrm{N}-\mathrm{C}$ bond angles around the fuseddiarylamine unit approaches $360^{\circ}$, suggesting $\mathrm{sp}^{2}$-like conformations of the embedded nitrogen atoms. The bond distances around the embedded nitrogen atoms of $\mathbf{1 3}$ remains unchanged even after one-electron oxidation due to the inherently rigid structure. On the other hand, the MPD of $[13]^{+}(0.092 \AA)$ is slightly smaller than that of the neutral species $13(0.104 \AA)$.

In the crystal, $[\mathbf{1 3}]^{+}$forms an offset face-to-face dimer with an interporphyrin separation of $3.354 \AA$, which is slightly smaller than a sum of van der Waals radii of two carbon atoms (3.40 $\mathrm{A}$ ). Importantly, the interporphyrin separation of $[13]^{+}$is distinctly shorter than that of neutral 13 (3.511 $\AA$ ) despite Coulomb's repulsion between the two cationic $\pi$-systems. The observed short interporphyrin separation of [13] $]^{+}$imply some associative interactions like SOMO-SOMO interaction as observed in planar radical cations. ${ }^{28}$ On the other hand, $[\mathbf{1 4}]^{+}$shows a one- dimensional columnar packing with an interporphyrin separation of $4.212 \AA$, which is longer than that of $\mathbf{1 4}(3.390 \AA)$. The different packing structure between $[\mathbf{1 3}]^{+}$and $[\mathbf{1 4}]^{+}$can be ascribed to the structural difference; almost planar for $[\mathbf{1 3}]^{+}$and partially twisted for $[\mathbf{1 4}]^{+}$. In accordance with this interpretation, overlap of the two $\pi$-planes is larger in $[\mathbf{1 3}]^{+}$than $[\mathbf{1 4}]^{+}$.

\section{Optical properties and excited-state decay-dynamics of radical cations}

The UV/Vis absorption spectra of $\mathbf{1 3}, \mathbf{1 4},[\mathbf{1 3}]^{+}$, and [14] $]^{+}$in $\mathrm{CH}_{2} \mathrm{Cl}_{2}$ are shown in Fig. 7. The neutral species 13 exhibits a Soret band at $455 \mathrm{~nm}$ with a shoulder at $402 \mathrm{~nm}$, and Q bands at 598 and $628 \mathrm{~nm}$. In contrast, the radical cation [13] $]^{+}$displays an ill-defined and largely red-shifted absorption spectrum with peaks at 403 , $467,543,609,677,1092$, and $1583 \mathrm{~nm}$. The faint broad absorption at around $1583 \mathrm{~nm}$ is characteristic of porphyrinoid radicals. ${ }^{6}$ Similarly, the radical cation of $\beta, \beta^{\prime}$-dichloro diphenylamine-fused porphyrin $[\mathbf{1 4}]^{+}$also shows a broad and largely red-shifted absorption spectrum with peaks at 441, 460,543,663, and $903 \mathrm{~nm}$, while the neutral species 14 displays a Soret band at $453 \mathrm{~nm}$ and Q bands at 570 and $615 \mathrm{~nm}$. The observed red-shifted absorption bands of $[\mathbf{1 3}]^{+}$compared to those of $[\mathbf{1 4}]^{+}$can be ascribed to the effective conjugation of the fused phenoxazine moiety.

We have investigated the excited-state decay-dynamics of 13, 14, $[13]^{+}$and $[\mathbf{1 4}]^{+}$by femtosecond transient absorption (TA) measurements. The TA spectra of $\mathbf{1 3}$ exhibited solvent-dependent decay-dynamics with time constants of 0.8 and 31 ps in methylcyclohexane, 0.5 and 18 ps in toluene, and 0.4 and 10 ps in $\mathrm{CH}_{2} \mathrm{Cl}_{2}$. Similarly, 14 also displayed solvent-dependent decaydynamics with time constants of 0.9 and $70 \mathrm{ps}$ in methylcyclohexane, 0.5 and $34 \mathrm{ps}$ in toluene, and 0.4 and $10 \mathrm{ps}$ in $\mathrm{CH}_{2} \mathrm{Cl}_{2}$. Then, their decay time constants increase according to a decrease of solvent polarity, suggesting the occurrence of an 
(a)

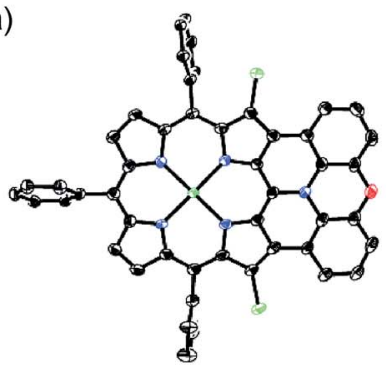

(c)

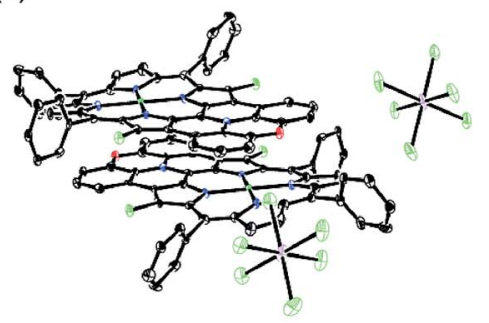

(f)

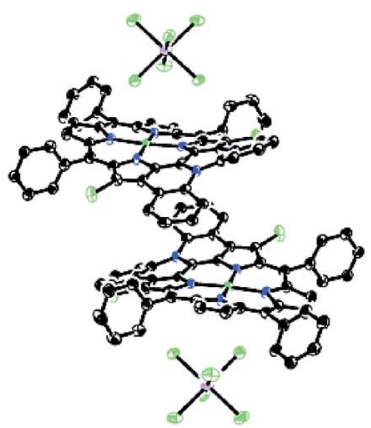

(b)

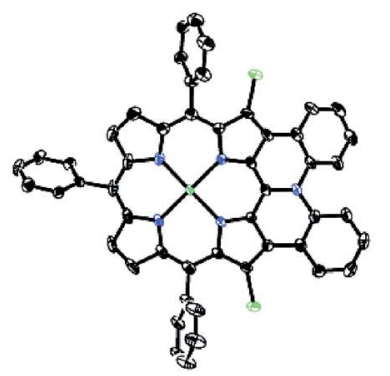

(d)

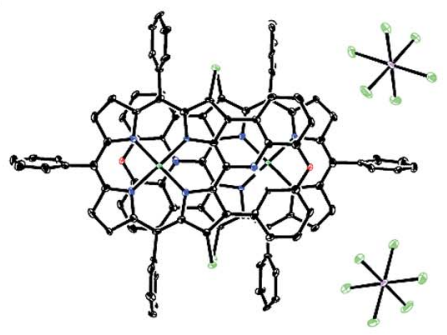

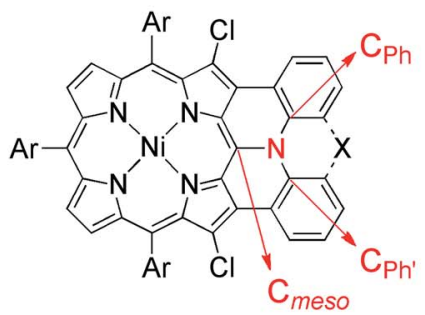

(e)

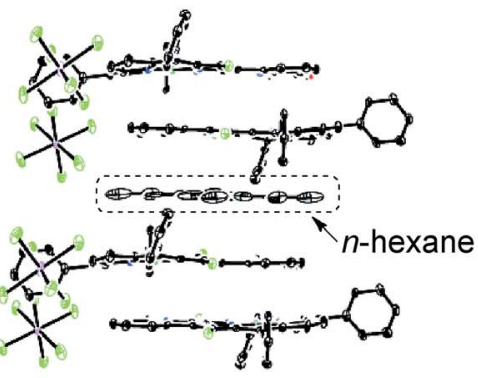

(g)

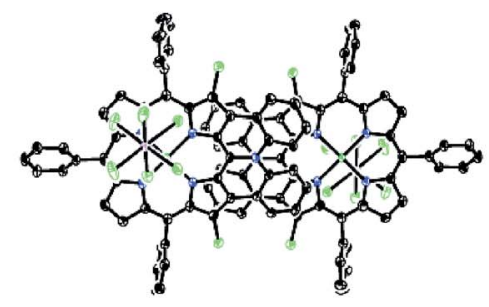

(h)

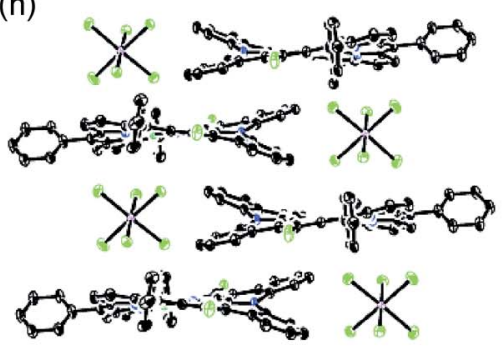

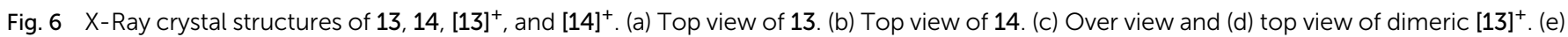
Side view of the packing structure of $[13]^{+}$. (f) Over view and (g) top view of dimeric [14] ${ }^{+}$. (h) Side view of the packing structure of $[14]^{+}$. Thermal ellipsoids are drawn at the $50 \%$ probability level for 13,14 and $[13]^{+}$, and the $30 \%$ probability level for $[14]^{+}$. Solvent molecules (except for $n$-hexane in (e)), tert-butyl groups, and all hydrogen atoms are omitted for clarity.

intramolecular charge transfer (CT) process in 13 and 14. Particularly, faster decay time constants were observed in $\mathbf{1 3}$ compared to 14, indicating a faster charge recombination process facilitated by effective $\pi$-conjugation in planar conformation of 13 . The TA spectra of $[\mathbf{1 3}]^{+}$and $[\mathbf{1 4}]^{+}$decay rapidly with time constants of 0.7 and $6.5 \mathrm{ps}$ for [13] $]^{+}$and 0.6 and $8.0 \mathrm{ps}$ for $[\mathbf{1 4}]^{+}$, respectively. These fast relaxation processes are assignable to internal conversion processes to the lowest excited state and the open-shell ground state, which is well-matched with the ultrafast relaxation dynamics of radical species due to their high density of states. ${ }^{6}$

To obtain more insights into the $\pi$-conjugation and radical nature, we conducted two photon absorption (TPA) measurements by using open-aperture Z-scan methods (see Fig. S68

Table 2 Selected bond lengths $(\AA)^{a}$, inner angles $(\mathrm{deg})^{a}, \operatorname{MPD}(\AA ̊)$, and interporphyrin separation $(\AA \AA)$ for $13,[13]^{+}, 14$, and $[14]^{+}$from $\mathrm{crystal}$ structures

\begin{tabular}{llllll}
\hline & & & & & \\
& $\mathrm{N}-\mathrm{C}_{\text {meso }}$ & $\mathrm{N}-\mathrm{C}_{\mathrm{Ph}}$ & $\angle \mathrm{C}_{\text {meso }}-\mathrm{N}-\mathrm{C}_{\mathrm{Ph}}$ & $\angle \mathrm{C}_{\mathrm{Ph}-\mathrm{N}-\mathrm{C}_{\mathrm{Ph}^{\prime}}}$ & $\begin{array}{l}\text { Interporphyrin } \\
\text { separation }\end{array}$ \\
\hline $\mathbf{1 3}^{b}$ & $1.393(4)$ & $1.413(2)$ & $121.1(2)$ & $117.9(3)$ & 0.104 \\
{$\left[\mathbf{1 3}^{+}\right.$} & $1.396(7)$ & $1.425(7)$ & $120.8(5)$ & $118.4(7)$ & 0.092 \\
$\mathbf{1 4}^{b}$ & $1.401(5)$ & $1.423(4)$ & $119.7(2)$ & $120.5(3)$ & 0.398 \\
{$\left[\mathbf{1 4}^{+}\right.$} & $1.388(10)$ & $1.423(6)$ & $120.2(4)$ & $119.7(6)$ & 3.354 \\
\end{tabular}

${ }^{a}$ The values were averaged for $C_{2 \mathrm{v}}$ symmetry. The estimated standard deviations of mean values were calculated from the experimental values using the following equation: $\delta(l)=1 /\left(\Sigma\left(1 / \delta_{i}^{2}\right)\right)^{1 / 2} \cdot{ }^{b}$ The values were averaged for two crystallographically independent molecules. The estimated standard deviations of mean values were calculated from the experimental values using the following equation: $\delta(l)=1 /\left(\Sigma\left(1 / \delta_{i}^{2}\right)\right)^{1 / 2}$. 


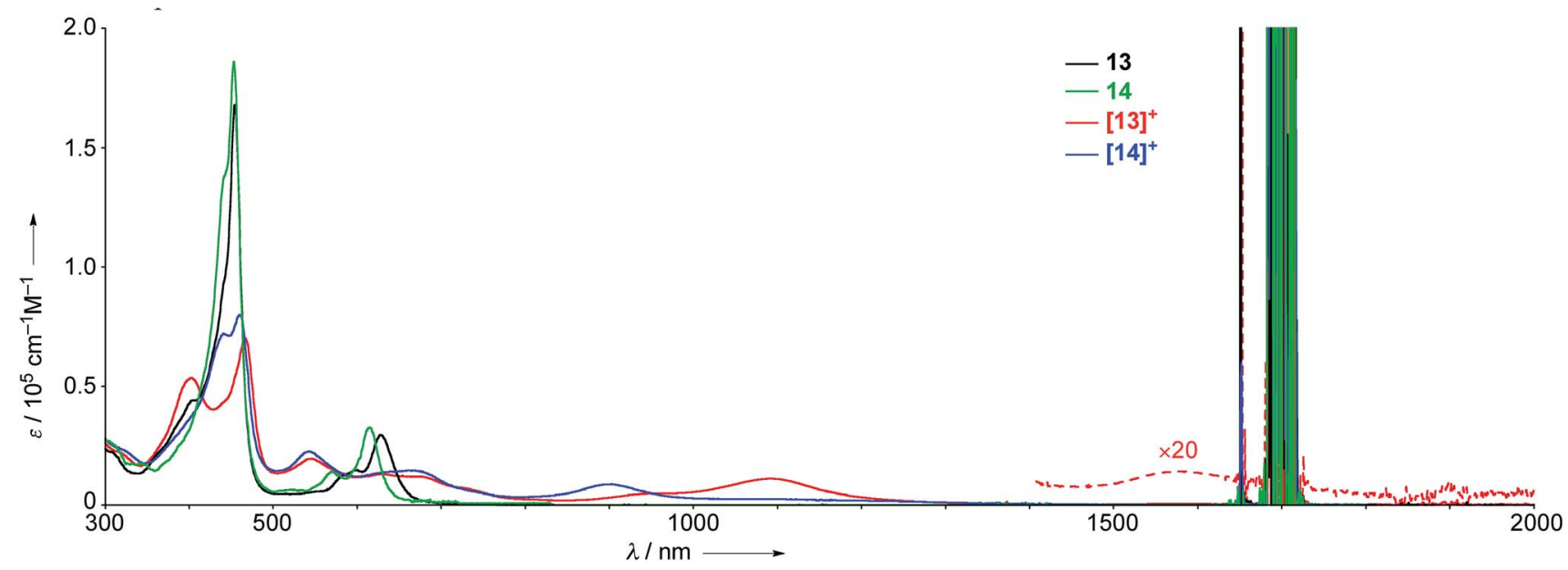

Fig. 7 UV/Vis absorption spectra of $13,14,[13]^{+}$, and $[14]^{+}$in $\mathrm{CH}_{2} \mathrm{Cl}_{2} \cdot \varepsilon=$ extinction coefficient.

and 69 in the ESI $\dagger$ ). The maximum TPA cross-section values of 13 and 14 were measured as 260 and $140 \mathrm{GM}$, respectively, at $1200 \mathrm{~nm}$. Compared to a small TPA cross-section value of typical porphyrins $(<100 \mathrm{GM}),{ }^{29}$ larger TPA cross-section values of $\mathbf{1 3}$ and $\mathbf{1 4}$ are comprehended by the extension of $\pi$-conjugation. ${ }^{9 a, 30}$ In the same regard, the larger TPA crosssection value of $\mathbf{1 3}$ compared with that of $\mathbf{1 4}$ may arise from $\pi$-system extension due to the fused phenoxazine group. For the radical cations $[\mathbf{1 3}]^{+}$and $[\mathbf{1 4}]^{+}$, the maximum TPA crosssection values were measured as $500 \mathrm{GM}$ at $2200 \mathrm{~nm}$, and 410 GM at $1800 \mathrm{~nm}$, respectively, which are almost twofold larger than their non-radical analogues 13 and 14. These largely enhanced TPA cross-section values of $[\mathbf{1 3}]^{+}$and $[\mathbf{1 4}]^{+}$can be ascribed to their radical characters. ${ }^{6 f}$

\section{Magnetic properties and DFT calculations}

Both the ${ }^{1} \mathrm{H}$ NMR spectra of $[\mathbf{1 3}]^{+}$and $[\mathbf{1 4}]^{+}$(from -2 to $12 \mathrm{ppm}$ ) in $\mathrm{CDCl}_{3}$ exhibited no signal except for two broad singlets due to the tert-butyl groups (ESI, Fig. S32 and S34†). Instead, the electron spin resonance (ESR) spectra of $[13]^{+}$and $[14]^{+}$in degassed toluene solutions at room temperature showed sharp signals at $g=2.0031$ and 2.0029, respectively, suggesting their $\pi$-radical characters (Fig. 8). The lack of hyperfine coupling may be attributed to the fast equilibrium between the monomer and dimer and/or small contribution of the $\mathrm{H}$ and $\mathrm{N}$ atoms to the spin delocalization.

$$
\begin{gathered}
\chi T=f_{1} \frac{N_{\mathrm{A}} g^{2} \mu_{\mathrm{B}}{ }^{2}}{k_{\mathrm{B}}\left[3+\exp \left(-2 J_{1} / k_{\mathrm{B}} T\right)\right]}+f_{2} \frac{N_{\mathrm{A}} g^{2} \mu_{\mathrm{B}}{ }^{2}}{2 k_{\mathrm{B}}} \\
\chi T=f \frac{N g^{2} \mu_{\mathrm{B}}{ }^{2}}{k_{\mathrm{B}}} \frac{0.25+0.14995 x+0.30094 x^{2}}{1+1.9862 x+0.68854 x^{2}+6.0626 x^{3}} \\
x=\frac{\left|J_{1}\right|}{k_{\mathrm{B}} T}
\end{gathered}
$$

The spin density of $[\mathbf{1 3}]^{+}$was calculated at the UB3LYP/6$31^{*}(\mathrm{C}, \mathrm{H}, \mathrm{N}, \mathrm{O}, \mathrm{Cl})+\mathrm{LANL} 2 \mathrm{DZ}(\mathrm{Ni})$ level using the Gaussian 09 program package ${ }^{31}$ excluding the counteranion, which was found to be delocalized over the whole $\pi$-system (Fig. 9). The spin density value of the embedded nitrogen atom $(+0.132)$ is significantly smaller than those of planarized triarylamines ${ }^{7 c, g}$ $(+0.328$ and +0.366$)$ due to the effective spin delocalization onto the porphyrin unit. The large spin densities at the three mesopositions apart from the fused nitrogen atom have been observed in other porphyrin $\pi$-radicals. ${ }^{6 \boldsymbol{a j}, \boldsymbol{k}, \boldsymbol{l}}$ In addition, chlorine-substituted $\beta$-positions show moderate contribution to the spin delocalization $(+0.101$ and +0.086$)$. Attempted calculations on $[\mathbf{4 N i}]^{+}$also exhibit similar spin density at the reactive $\beta$-positions (+0.111 and +0.095$)$ (ESI, Fig. S62 $\dagger$ ), emphasizing the necessity for steric protection. ${ }^{6 g}$ In contrast, the central nickel atom displays negligible spin density, suggesting that $[13]^{+}$is a $\pi$-radical having a two-valent nickel center.

The magnetic properties of $[\mathbf{1 3}]^{+}$and $[\mathbf{1 4}]^{+}$in the solid (powder) states were examined by temperature-dependent magnetic susceptibility measurements (SQUID) at $0.5 \mathrm{~T}$ from 2 to $350 \mathrm{~K}$ for $[13]^{+}$and from 2 to $300 \mathrm{~K}$ for $[14]^{+}$(Fig. 10). The observed $\chi T$ values of $[\mathbf{1 3}]^{+}$and $[\mathbf{1 4}]^{+}$clearly indicated the different degrees of magnetic interaction. The observed low $\chi T$ values of $[\mathbf{1 3}]^{+}$might be induced by the break down of the crystal structure originating from the defect of the solvent molecules. Although the magnetic analyses were conducted for the powder
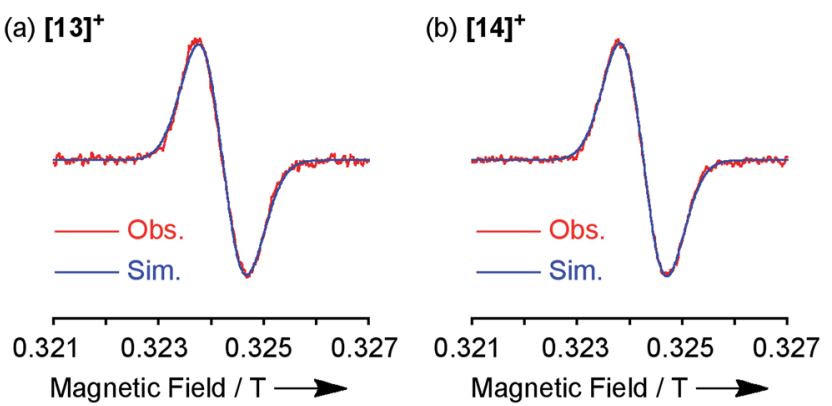

Fig. 8 ESR spectra observed at room temperature and the corresponding simulated spectra of (a) $[13]^{+}$and (b) $[14]^{+}$. 

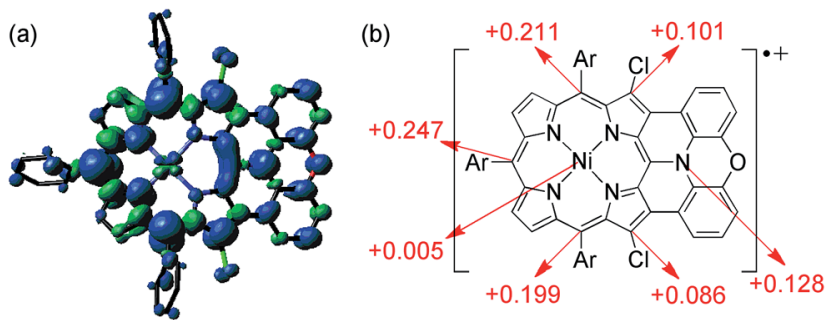

Fig. 9 (a) Spin density distribution and (b) selected values of [13] ${ }^{+}$ calculated at the UB3LYP/6-31G* $(\mathrm{C}, \mathrm{H}, \mathrm{N}, \mathrm{O}, \mathrm{Cl})+\mathrm{LANL} 2 \mathrm{DZ}(\mathrm{Ni})$ level (isovalue: 0.001; the molecular geometry was optimized based on the $\mathrm{X}$-ray crystal structure).

samples, it may be considered that the molecules should take packing structures similar to their single crystals in a microscopic sense. Namely, [13] ${ }^{+}$will adopt an offset face-to-face dimer while $[\mathbf{1 4}]^{+}$will take a one-dimensional columnar arrangement. According to these assumptions, the $\chi T$ values of $[13]^{+}$and $[\mathbf{1 4}]^{+}$obeyed the Bleaney-Bowers singlet-triplet model $^{32}$ (eqn (1)) and Bonner-Fisher model ${ }^{33}$ (eqn (2) and (3)), respectively. The parameters $J_{1} / k_{\mathrm{B}}$ of $[\mathbf{1 3}]^{+}$and $[\mathbf{1 4}]^{+}$are -30.4 and $-1.6 \mathrm{~K}$, respectively. The small absolute value of $J_{1} / k_{\mathrm{B}}$ in $[\mathbf{1 4}]^{+}$indicates the very weak intermolecular antiferromagnetic interaction. In contrast, $[\mathbf{1 3}]^{+}$exhibits relatively strong antiferromagnetic interaction, reflecting the large overlap and short separation between the two $\pi$-systems in the crystal structure.

\section{Conclusions}

Oxidative fusion reaction of meso-phenoxazino Ni(II) porphyrin 7 was found to be temperature dependent. Doubly phenoxazinefused porphyrin $\mathbf{4 N i}$ was synthesized by stepwise oxidation of meso-phenoxazino $\mathrm{Ni}(\mathrm{II})$ porphyrin 7 at high temperature, and was converted to the corresponding free base porphyrin $\mathbf{4 H}_{\mathbf{2}}$ and Zn(II) porphyrin $\mathbf{4 Z n}$. The X-ray structure analysis of $\mathbf{4 N i}$ revealed its fairly planar structure and an offset pairing with a small interporphyrin separation in the crystal. Similar effective $\pi-\pi$ stacking dimerization in $\mathrm{CDCl}_{3}$ was also indicated by ${ }^{1} \mathrm{H}$ NMR titration. The cyclic voltammetry of $4 \mathbf{N i}$ exhibited a characteristic split first oxidation wave, indicating the generation of a mixed-valence $\pi$-radical cation dimer upon

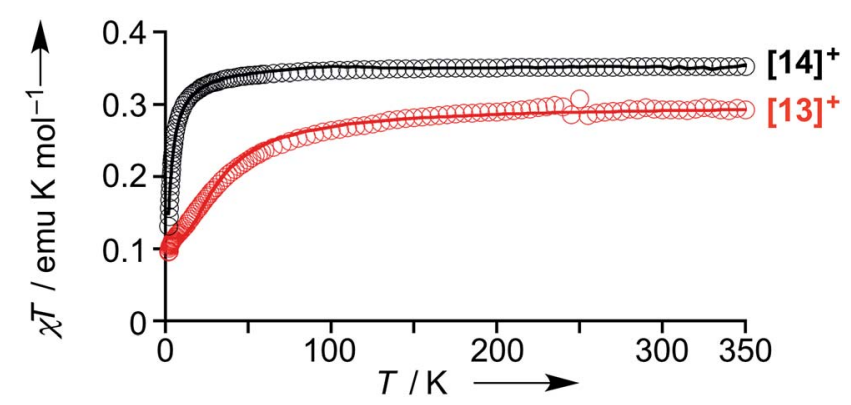

Fig. 10 Temperature-dependent magnetic susceptibility in the solid states of $[13]^{+}$(red) and $[14]^{+}$(black). Circles: observed; solid line: simulated. electrochemical oxidation. The fused porphyrins $\mathbf{4} \mathbf{H}_{\mathbf{2}}$ and $\mathbf{4 Z n}$ show large fluorescence quantum yields as compared to those of the diphenylamine-fused counterpart $\mathbf{1 0 H}_{2}$ and $\mathbf{1 0 Z n}$.

One-electron oxidation of $\mathbf{4 N i}$ with Magic Blue gave stable radical cation $[\mathbf{4 N i}]^{+}$, which was isolated via separation over a silica gel column in open air but was slowly chlorinated at the reactive $\beta$-positions. $\beta, \beta$-Dichlorinated radical cations $[13]^{+}$and $[\mathbf{1 4}]^{+}$were much more stable and could be stored for over several months without any degradation under ambident conditions. In the solid states, $[\mathbf{1 3}]^{+}$showed distinctly larger antiferromagnetic interaction than that of $[\mathbf{1 4}]^{+}$owing to the more tightly packed dimeric unit arising from its planar structure. Further investigations are underway to create other stable porphyrin radical cations in our laboratory.

\section{Acknowledgements}

The work at Kyoto was supported by Grants-in-Aid from MEXT (No. 25107002 "Science of Atomic Layers"), from JSPS (No. 25220802 (Scientific Research (S)), 24685007 (Young Scientists (A)), 26620081 (Exploratory Research)), and ACT-C, JST. N. F. acknowledges a JSPS Fellowship for Young Scientists. H. Y. acknowledges Kansai Research Foundation for Technology Promotion and Asahi Glass Foundation for financial support. The work at Yonsei was supported by the Global Research Laboratory (GRL) Program (2013K1A1A2A02050183) of the Ministry of Education, Science and Technology (MEST) of Korea.

\section{Notes and references}

1 Selected reviews for photosynthesis: (a) M. R. Wasielewski, Chem. Rev., 1992, 92, 435; (b) D. Gust, T. A. Moore and A. L. Moore, Acc. Chem. Res., 2001, 34, 40; (c) S. Fukuzumi, K. Ohkubo and T. Suenobu, Acc. Chem. Res., 2014, 47, 1455. Selected reviews for enzymatic oxidation cycles of cytochrome P-450: (d) R. E. White and M. J. Coon, Annu. Rev. Biochem., 1980, 49, 315; (e) M. Sono, M. P. Roach, E. D. Coulter and J. H. Dawson, Chem. Rev., 1996, 96, 2841; (f) P. Hlavica, Eur. J. Biochem., 2004, 271, 4335.

$2(a) \quad$ R. H. Felton, Primary Redox Reactions of Metalloporphyrins: The Porphyrins, ed. D. Dolphin, Academic Press, New York, 1978, vol. 5, pp. 53-125; (b) J.-H. Fuhrhop and D. Mauzerall, J. Am. Chem. Soc., 1968, 90, 3875; (c) R. H. Felton, D. Dolphin, D. C. Borg and J. Fajer, J. Am. Chem. Soc., 1969, 91, 196; (d) A. Wolberg and J. Manassen, J. Am. Chem. Soc., 1970, 92, 2982; (e) A. Wolberg and J. Manassen, Inorg. Chem., 1970, 9, 2365; (f) J. Fajer, D. C. Borg, A. Forman, A. D. Adler and V. Varad, J. Am. Chem. Soc., 1974, 96, 1238.

3 (a) W. F. Scholz and C. A. Reed, J. Am. Chem. Soc., 1982, 104, 6791; (b) P. Gans, G. Buisson, E. Duée, J.-C. Marchon, B. S. Erler, W. F. Scholz and C. A. Reed, J. Am. Chem. Soc., 1986, 108, 1223; (c) H. Song, R. D. Orosz, C. A. Reed and W. R. Scheidt, Inorg. Chem., 1990, 29, 4274; (d) W. R. Scheidt, K. E. Brancato-Buentello, H. Song, K. V. Reddy and B. Cheng, Inorg. Chem., 1996, 35, 7500; (e) 
K. M. Barkigia, M. W. Renner and J. Fajer, J. Phys. Chem. B, 1997, 101, 8398; $(f)$ R.-J. Cheng, C.-H. Ting, T.-C. Chao, T.-H. Tseng and P. P.-Y. Chen, Chem. Commun., 2014, 50, 14265.

4 (a) J. T. Groves, R. C. Haushalter, M. Nakamura, T. E. Nemo and B. J. Evans, J. Am. Chem. Soc., 1981, 103, 2884; (b) S. Tsuchiya, J. Chem. Soc., Chem. Commun., 1991, 716.

5 R. G. Hicks, Stable Radicals: Fundamentals and Applied Aspects of Odd-Electron Compounds, Wiley-Blackwell, New York, 2010.

6 (a) R. G. Khoury, L. Jaquinod, A. M. Shachter, N. Y. Nelson and K. M. Smith, Chem. Commun., 1997, 215; (b) S. Hiroto, K. Furukawa, H. Shinokubo and A. Osuka, J. Am. Chem. Soc., 2006, 128, 12380; (c) T. Koide, G. Kashiwazaki, M. Suzuki, K. Furukawa, M.-C. Yoon, S. Cho, D. Kim and A. Osuka, Angew. Chem., Int. Ed., 2008, 47, 9661; (d) M. Ishida, J.-Y. Shin, J. M. Lim, B. S. Lee, M.-C. Yoon, T. Koide, J. L. Sessler, A. Osuka and D. Kim, J. Am. Chem. Soc., 2011, 133, 15533; (e) D. Shimizu, J. Oh, K. Furukawa, D. Kim and A. Osuka, Angew. Chem., Int. Ed., 2015, 54, 6613; (f) Y. Hisamune, K. Nishimura, K. Isakari, M. Ishida, S. Mori, S. Karasawa, T. Kato, S. Lee, D. Kim and H. Furuta, Angew. Chem., Int. Ed., 2015, 54, 7323; $(g)$ P. Schweyen, K. Brandhorst, R. Wicht, B. Wolfram and M. Bröring, Angew. Chem., Int. Ed., 2015, 54, 8213; (h) Y. Tanaka, T. Yoneda, K. Furukawa, T. Koide, H. Mori, T. Tanaka, H. Shinokubo and A. Osuka, Angew. Chem., Int. Ed., 2015, 54, 10908; (i) T. Yoshida, W. Zhou, T. Furuyama, D. B. Leznoff and N. Kobayashi, J. Am. Chem. Soc., 2015, 137, 9258; (j) D. Shimizu, J. Oh, K. Furukawa, D. Kim and A. Osuka, J. Am. Chem. Soc., 2015, 137, 15584; (k) L. J. Esdaile, L. Rintoul, M. S. Goh, K. Merahi, N. Parizel, R. M. Wellard, S. Choua and D. P. Arnold, Chem.-Eur. J., 2016, 22, 3430.

7 (a) D. Hellwinkel and M. Melan, Chem. Ber., 1974, 107, 616; (b) D. Bamberger, D. Hellwinkel and F. A. Neugebauer, Chem. Ber., 1975, 108, 2416; (c) M. Kuratsu, M. Kozaki and K. Okada, Angew. Chem., Int. Ed., 2005, 44, 4056; (d) M. Kuratsu, S. Suzuki, M. Kozaki, D. Shiomi, K. Sato, T. Takui and K. Okada, Inorg. Chem., 2007, 46, 10153; (e) M. Takase, V. Enkelmann, D. Sebastiani, M. Baumgarten and K. Müllen, Angew. Chem., Int. Ed., 2007, 46, 5524; (f) M. Takase, T. Narita, W. Fujita, M. S. Asano, T. Nishinaga, H. Benten, K. Yoza and K. Müllen, J. Am. Chem. Soc., 2013, 135, 8031; (g) X. Zheng, X. Wang, Y. Qiu, Y. Li, C. Zhou, Y. Sui, Y. Li, J. Ma and X. Wang, J. Am. Chem. Soc., 2013, 135, 14912.

8 E. T. Seo, R. F. Nelson, J. M. Fritsch, L. S. Marcoux, D. W. Leedy and R. N. Adams, J. Am. Chem. Soc., 1966, 98, 3498.

9 (a) N. Fukui, W.-Y. Cha, S. Lee, S. Tokuji, D. Kim, H. Yorimitsu and A. Osuka, Angew. Chem., Int. Ed., 2013, 52, 9728; (b) N. Fukui, H. Yorimitsu and A. Osuka, Angew. Chem., Int. Ed., 2015, 54, 6311.

10 Gryko et al. also reported a singly dinaphthylamine-fused porphyrin, independently. A. Nowak-Król and D. T. Gryko, Org. Lett., 2013, 15, 5618.
11 N. Fukui, S.-K. Lee, K. Kato, D. Shimizu, T. Tanaka, S. Lee, H. Yorimitsu, D. Kim and A. Osuka, Chem. Sci., 2016, 7, 4059. 12 (a) N. A. Cortese and R. F. Heck, J. Org. Chem., 1977, 42, 3491; (b) A. K. Sahoo, Y. Nakamura, N. Aratani, K. S. Kim, S. B. Noh, H. Shinokubo, D. Kim and A. Osuka, Org. Lett., 2006, 18, 4141.

13 2-(2',6'-Dimethoxybiphenyl)dicyclohexylphosphine (SPhos): T. E. Barder, S. D. Walker, J. R. Martinelli and S. L. Buchwald, J. Am. Chem. Soc., 2005, 127, 4685.

14 K. Murakami, Y. Yamamoto, H. Yorimitsu and A. Osuka, Chem.-Eur. J., 2013, 19, 9123.

15 J.-P. Strachan, S. Gentemann, J. Seth, W. A. Kalsbeck, J. S. Lindsey, D. Holten and D. F. Bocian, J. Am. Chem. Soc., 1997, 119, 11191.

16 Crystallographic data for $2 \mathrm{Ni}: \mathrm{C}_{74} \mathrm{H}_{77} \mathrm{~N}_{5} \mathrm{Ni} \cdot \mathrm{CHCl}_{3} \cdot \mathrm{CH}_{3} \mathrm{CN}$, monoclinic, space group $C 2 / c$ (no. 15), $a=36.653(7) \AA, b=$ 21.504(4) $\mathrm{A}, c=17.115(3) \AA, \beta=98.833(2)^{\circ}, V=13330(4) \AA^{3}$, $T=93 \mathrm{~K}, Z=8, R_{1}=0.0768(I>2 \sigma(I)), R_{\mathrm{w}}=0.2444$ (all data), $\mathrm{GOF}=1.047$. CCDC number: 1469154 . Crystallographic data for $3 \mathrm{Ni}: \mathrm{C}_{74} \mathrm{H}_{75} \mathrm{~N}_{5} \mathrm{NiO} \cdot\left(\mathrm{C}_{6} \mathrm{H}_{5} \mathrm{CH}_{3}\right)_{1.5}$, monoclinic, space group $P 2_{1} / n$ (no. 14), $a=21.181(7) \AA$, $b=10.751(4) \AA, c=29.482(10) \AA, \beta=100.128(9)^{\circ}, V=$ $6609(4) \AA^{3}, T=93 \mathrm{~K}, Z=4, R_{1}=0.0714(I>2 \sigma(I)), R_{\mathrm{w}}=$ 0.2075 (all data), GOF $=1.029$. CCDC number: 1469155 .

17 The MPD of $\mathbf{1 0 N i}$ is defined by the 38 core atoms consisting of meso-carbons, four pyrrole units, central nickel atom, and fused-diphenylamine unit. The MPD of $4 \mathbf{N i}$ is defined by the 39 core atoms consisting of four pyrrole units, central nickel atom, and fused-phenoxazine unit.

18 (a) A. S. Shetty, J. Zhang and J. S. Moore, J. Am. Chem. Soc., 1996, 118, 1019; (b) Y. Tobe, N. Utsumi, K. Kawabata, A. Nagano, K. Adachi, S. Araki, M. Sonoda, K. Hirose and K. Naemura, J. Am. Chem. Soc., 2002, 124, 5350; (c) J. Wu, A. Fechtenkötter, J. Gauss, M. D. Watson, M. Kastler, C. Fechtenkötter, M. Wagner and K. Müllen, J. Am. Chem. Soc., 2004, 126, 11311; (d) C.-J. Wallentin, T. Wixe, O. F. Wendt, K.-E. Bergquist and K. Wärnmark, Chem.-Eur. J., 2010, 16, 3994.

19 M. Saunders and J. B. Hyne, J. Chem. Phys., 1958, 20, 1319. 20 I. Horman and B. Dreux, Helv. Chim. Acta, 1984, 67, 754.

21 K. Fujimoto, J. Oh, H. Yorimitsu, D. Kim and A. Osuka, Angew. Chem., Int. Ed., 2016, 55, 3196.

22 (a) K. M. Kadish, D. Sazou, Y. M. Liu, A. Saoiabi, M. Ferhat and R. Guilard, Inorg. Chem., 1988, 27, 686; (b) A. Giraudeau, A. Louati, M. Gross, J. J. Andre, J. Simon, C. H. Su and K. M. Kadish, J. Am. Chem. Soc., 1983, 105, 2917; (c) D. Gut, I. Goldberg and M. Kol, Inorg. Chem., 2003, 42, 3483; (d) S. D. Bergman, I. Goldberg, A. Barbieri, F. Barigelletti and M. Kol, Inorg. Chem., 2004, 43, 2355; (e) N. R. d. Tacconi, R. Chitakunye, F. M. MacDonnell and R. O. Lezna, J. Phys. Chem. A, 2008, 112, 497; (f) M. A. Christensen, C. R. Parker, T. J. Sørensen, S. d. Graaf, T. J. Morsing, T. Brock-Nannestad, J. Bendix, M. M. Haley, P. Rapta, A. Danilov, S. Kubatkin, O. Hammerich and M. B. Nielsen, J. Mater. Chem. C, 2014, 2, 10428; $(g)$ M. A. Christensen, G. E. Rudebusch, C. R. Parker, 
C. L. Anderson, A. Kadziola, M. M. Haley, O. Hammerich and M. B. Nielsen, RSC Adv., 2015, 5, 49748.

23 R. Sakamoto, M. Nishikawa, T. Yamamura, S. Kume and H. Nishihara, Chem. Commun., 2010, 46, 2028.

24 (a) Y. L. Mest, M. L'Her, N. H. Hendricks, K. Kim and J. P. Collman, Inorg. Chem., 1992, 31, 835; (b) Y. Matano, K. Matsumoto, Y. Terasaka, H. Hotta, Y. Araki, O. Ito, M. Shiro, T. Sasamori, N. Tokitoh and H. Imahori, Chem.Eur. J., 2007, 13, 891.

25 R. A. Rodriguez, C.-M. Pan, Y. Yabe, Y. Kawamata, M. D. Eastgate and P. S. Baran, J. Am. Chem. Soc., 2014, 136, 6908.

26 (a) F. Cozzi and J. S. Siegel, Pure Appl. Chem., 1995, 67, 683; (b) M. J. Rashkin and M. L. Waters, J. Am. Chem. Soc., 2002, 124, 1860.

27 Crystallographic data for 8: $\left(\mathrm{C}_{74} \mathrm{H}_{73} \mathrm{Cl}_{2} \mathrm{~N}_{5} \mathrm{NiO}\right)_{2} \cdot\left(\mathrm{CHCl}_{3}\right)_{1.5}$, triclinic, space group $P \overline{1}$ (no. 2), $a=18.141(3) \AA, b=$ 20.0791(19) $\AA, c=20.299(2) \AA, \alpha=62.0374(10)^{\circ}, \beta=$ 79.030(16) $)^{\circ}, \gamma=87.782(14)^{\circ}, V=6400.6(14) \AA^{3}, T=93 \mathrm{~K}$, $Z=2, R_{1}=0.0791(I>2 \sigma(I)), R_{\mathrm{w}}=0.2451$ (all data), GOF $=$ 1.045. CCDC number: 1469157. Crystallographic data for $[8]^{+}: \quad \mathrm{C}_{74} \mathrm{H}_{73} \mathrm{Cl}_{2} \mathrm{~N}_{5} \mathrm{NiO} \cdot \mathrm{SbCl}_{6} \cdot\left(\mathrm{C}_{6} \mathrm{H}_{14}\right)_{2} \cdot \mathrm{CH}_{2} \mathrm{Cl}_{2}$, tetragonal, space group $I 4_{1} / a$ (no. 88), $a=57.941(6) \AA$, $b=57.941(6) \AA$, $c=10.6631(12) \AA, V=35798(8) \AA^{3}, T=93 \mathrm{~K}, Z=16, R_{1}=$ $0.0992(I>2 \sigma(I)), R_{\mathrm{w}}=0.2692$ (all data), GOF $=1.079$. CCDC number: 1469158. Crystallographic data for 9: $\left(\mathrm{C}_{74} \mathrm{H}_{75} \mathrm{Cl}_{2} \mathrm{~N}_{5} \mathrm{Ni}\right)_{2} \cdot\left(\mathrm{CHCl}_{3}\right)_{1.5} \cdot \mathrm{C}_{3} \mathrm{H}_{7} \mathrm{OH}$, monoclinic, space group $C 2 / c$ (no. 15), $a=72.720(9) \AA$, $b=13.4081(16) \AA$, $c=$ 33.152(4) $\mathrm{A}, \beta=102.869(4)^{\circ}, V=31513(7) \AA 30, T=93 \mathrm{~K}$, $Z=8, R_{1}=0.0996(I>2 \sigma(I)), R_{\mathrm{w}}=0.2800$ (all data), GOF $=$ 1.064. CCDC number: 1469159. Crystallographic data for [9]+: $\mathrm{C}_{74} \mathrm{H}_{75} \mathrm{Cl}_{2} \mathrm{~N}_{5} \mathrm{Ni} \cdot \mathrm{SbCl}_{6} \cdot\left(\mathrm{CH}_{2} \mathrm{Cl}_{2}\right)_{0.5}$, monoclinic, space group $P 21 / n$ (no. 14), $a=27.888(11) \AA, b=9.758(3) \AA, c=$ $29.846(11) \AA, \beta=113.508(6)^{\circ}, V=7448(5) \AA^{3}, T=93 \mathrm{~K}, Z=$ $4, R_{1}=0.0826(I>2 \sigma(I)), R_{\mathrm{w}}=0.2363$ (all data), GOF $=$ 1.004. CCDC number: 1469160.

28 (a) T. Nishinaga and K. Komatsu, Org. Biomol. Chem., 2005, 3, 561; (b) M. Tateno, M. Takase, M. Iyoda, K. Komatsu and T. Nishinaga, Chem.-Eur. J., 2013, 19, 5457.

29 T. K. Ahn, K. Kim, D. Y. Kim, S. B. Noh, N. Aratani, C. Ikeda, A. Osuka and D. Kim, J. Am. Chem. Soc., 2006, 128, 1700.

30 (a) P. Kim, S. Ham, J. Oh, H. Uoyama, H. Watanabe, K. Tagawa, H. Uno and D. Kim, Phys. Chem. Chem. Phys., 2013, 15, 10612; (b) W. Zeng, S. Lee, M. Son, M. Ishida, K. Furukawa, P. Hu, Z. Sun, D. Kim and J. Wu, Chem. Sci., 2015, 6, 2427.

31 M. J. Frisch, et al., Gaussian 09, Revision A.02, Gaussian, Inc., Wallingford, CT, 2009.

32 B. Bleaney and K. D. Bowers, Proc. R. Soc. London, Ser. A, 1952, 214, 451.

33 (a) J. C. Bonner and M. E. Fisher, Phys. Rev., 1964, 135, A640; (b) W. E. Estes, D. P. Gavel, W. E. Hatfield and D. J. Hodgson, Inorg. Chem., 1978, 17, 1415. 